\title{
Redox processes at iron hydroxide layers formed on platinum substrates in alkaline solutions
}

\author{
M. C. GALINDO*, M. E. MARTINS, J. R. VILCHE, A. J. ARVIA \\ Instituto de Investigaciones Fisicoquimicas Teóricas y Aplicadas (INIFTA), Facultad de Ciencias Exactas, \\ Universidad Nacional de La Plata. Sucursal 4, Casilla de Correo 16, 1900 La Plata, Argentina
}

Received 25 April 1988; revised 8 November 1988

Redox processes taking place at precipitated hydrous iron hydroxide layers chemically formed on platinum substrates in sodium hydroxide solutions are investigated at $25^{\circ} \mathrm{C}$. The electrochemical behaviour of these layers depends considerably on the electroreduction level reached in chargedischarge cycles. The accumulation of $\mathrm{Fe}_{3} \mathrm{O}_{4}$ during oxidation-reduction cycles can produce an increasing irreversibility of the $\mathrm{Fe}$ (II)/Fe(III) redox couple. Data are compared to results obtained with iron hydroxide layers formed by electrochemical and chemical methods on massive iron electrodes. Results are discussed in terms of a composite structure for the iron hydroxide layers.

\section{Introduction}

Redox processes involving iron hydroxide layers are of particular interest in corrosion and passivity of ferrous materials $[1-8]$ and in the charge/discharge cycles of the negative electrode in $\mathrm{Ni}-\mathrm{Fe}$ battery cells [9-12]. The available literature on those reactions is concerned mostly with kinetic data resulting from different types of oxide layers in contact with iron electrodes $[1-8,13-19]$. Although the structure of these layers has been extensively investigated both in situ [20-31] and ex situ [32-35], it is still highly controversial. Various interpretations of the oxide layer structures have been advanced either as a single film structure $[36,37]$ or a duplex or multiple layer structure [28-31]. Probably the disagreements are largely due to the fact that the composition and the structure of the iron hydroxide-oxide layers depend on the formation condition and applied potentials. Hence, one way of tackling the problem is to study a system where the number of processes involved in the overall electrochemical reaction is appreciably reduced. Thus, it appears reasonable to try a separation of the electrochemical reactions occurring at the metal hydroxide layer itself from those involving the proper substrate. This situation can be easily approached through the use of metal hydroxide layer electrodes made on conducting substrates [1, 3, 38-42] which proved to be electrochemically inactive in the potential range of the metal hydroxide electrode reactions. The preparation of this type of electrode may be achieved either through electrochemical of chemical procedures $[38,39]$. In the present work the electrochemical behaviour of iron hydroxide electrodes prepared by chemical precipitations on a platinum substrate is investigated.

\section{Experimental details}

The experimental set-up and the electrode preparation procedures were the same as already described in previous publications $[38,39]$. The working electrodes consisted of layers of chemically precipitated iron hydroxide on a clean platinum wire ('Specpure', Johnson Matthey Chemicals Ltd., $0.5 \mathrm{~mm}$ diameter, $0.21 \mathrm{~m}^{2}$ apparent area) made by alternate and repetitive substrate immersion in $z \mathrm{M} \mathrm{FeSO}{ }_{4}$ solution $(0.01 \leqslant z \leqslant 0.1)$ and in $x \mathrm{M} \mathrm{KOH}+y \mathrm{M} \mathrm{K}_{2} \mathrm{SO}_{4}$ solution $(0.01 \leqslant x \leqslant 0.01 ; 0 \leqslant y \leqslant 0.3)$. The immersion time in each solution was set at $5 \mathrm{~s}$ and the number of alternate immersions $(n)$ was varied from 5 up to 50 . Immediately after the electrode preparation, it was dipped into the cell containing $0.1 \mathrm{M} \mathrm{KOH}$, at $25^{\circ} \mathrm{C}$, under purified $\mathrm{N}_{2}$ saturation, and polarized for a time $\tau_{0}$ at the different potentials, $E_{\mathrm{i}}$, preset within the range where the most important electrochemical reactions of iron hydroxide take place. For comparison some measurements were also carried out with highpurity polycrystalline iron electrodes and iron hydroxide layers chemically precipitated on massive iron electrodes. Redox reactions involving the $\mathrm{K}_{4}\left[\mathrm{Fe}(\mathrm{CN})_{6}\right] /$ $\mathrm{K}_{3} \mathrm{Fe}(\mathrm{CN})_{6}$ ] system in $0.1 \mathrm{M} \mathrm{KOH}$ were also made using the iron hydroxide electrodes. The concentration of the equimolar redox system was $0.005 \mathrm{M}$.

Potentials were measured against an SCE, properly shielded, but in the test they are referred to the NHE scale. The following perturbing potential programmes $(E / t)$ were applied to the working electrodes: (i) conventional triangular potential sweeps either single (STPS) or repetitive (RTPS) between preset cathodic $\left(E_{\mathrm{s}, \mathrm{c}}\right)$ and anodic $\left(E_{\mathrm{s}, \mathrm{a}}\right)$ switching potentials at different potential sweep rates $\left(0.001 \mathrm{~V} \mathrm{~s}^{-1} \leqslant v \leqslant 0.1 \mathrm{~V} \mathrm{~s}^{-1}\right)$; (ii) constant potential steps; (iii) combined either

* Present address: Instituto de Química-Física, Facultad de Bioquímica, Química y Farmacia, Universidad Nacional de Tucumán. Ayacucho 491, (4000) Tucumán, Argentina. 


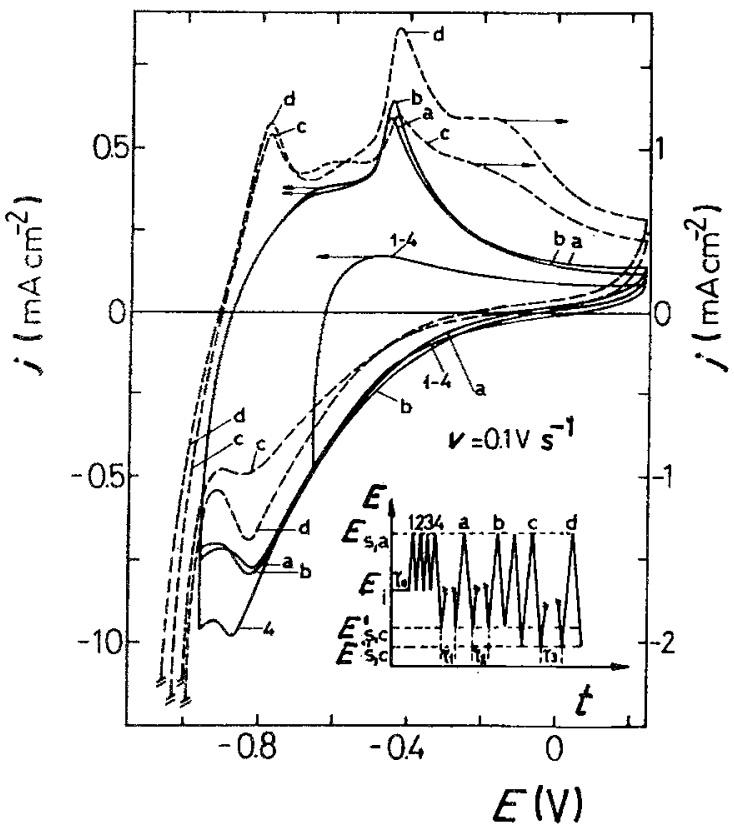

Fig. 1. Influence of the cathodic switching potential on the voltammograms obtained with an iron electrode in $0.1 \mathrm{M} \mathrm{KOH}$ solution at $v=0.1 \mathrm{~V} \mathrm{~s}^{-1}$. The perturbing potential programme is shown in the figure. $E_{\mathrm{i}}=-0.66 \mathrm{~V} ; \quad E_{\mathrm{s}, \mathrm{a}}=0.24 \mathrm{~V} ; \quad E_{\mathrm{s}, \mathrm{c}}^{\prime}=-0.96 \mathrm{~V}, \quad E_{\mathrm{s}, \mathrm{c}}^{\prime \prime}=$ $-1.16 \mathrm{~V} ; \tau_{0}=1 \mathrm{~min} ; \tau_{1}=6 \mathrm{~min} ; \tau_{2}=30 \mathrm{~min} ; \tau_{3}=1.5 \mathrm{~min}$.

STPS or RTPS with different potential steps. The iron concentration in the precipitated layer, before and after the proper electrochemical runs, was determinated by atomic absorption spectrometry (Rank Hilger Atmospek H 1550).

\section{Resuits}

Reference voltammograms for massive iron electrodes in $0.1 \mathrm{M} \mathrm{KOH}$ were recorded at $v=0.1 \mathrm{~V} \mathrm{~s}^{-1}$ between $E_{\mathrm{s}, \mathrm{a}}=0.24 \mathrm{~V}$ and different $E_{\mathrm{s}, \mathrm{c}}$ values to identify the potential ranges of the different electrooxidation and electroreduction processes (Figs 1 and 2). For $E_{\mathrm{s}, \mathrm{c}}=$ $E_{\mathrm{i}}=-0.66 \mathrm{~V}$ the stationary voltammogram is rapidly attained during cycling and the electrochemical response in the vicinity of $E_{\mathrm{s}, \mathrm{c}}$ becomes highly reversible (curves 1-4 in Fig. 1), although no conjugated pair of current peaks can be observed except a rather wide asymmetric anodic peak at ca $-0.48 \mathrm{~V}$. This voltammogram resembles that reported in the literature for an $\mathrm{Fe} / \mathrm{Fe}_{3} \mathrm{O}_{4}$ electrode [7]. As $E_{\mathrm{s}, \mathrm{c}}$ is set at $E_{\mathrm{s}, \mathrm{c}}=$ $E_{s, c}^{\prime}=-0.96 \mathrm{~V}$, an anodic current peak at ca. $-0.45 \mathrm{~V}$ and a cathodic peak at ca. $-0.85 \mathrm{~V}$ can be seen (curves a and $b$ in Fig. 1). Otherwise, as $E_{\mathrm{s}, \mathrm{c}}$ is set in the net HER potential range, i.e. $E_{\mathrm{s}, \mathrm{c}}=E_{\mathrm{s}, \mathrm{c}}^{\prime \prime}=$ $-1.16 \mathrm{~V}$, the voltammogram shows a multiplicity of anodic and cathodic peaks (dashed curves $\mathrm{c}$ and $\mathrm{d}$ in Fig. 1). Correspondingly, the voltammetric charge increases considerably during prolonged potential cycling and the stationary voltammogram resulting after $60 \mathrm{~min}$ potential cycling under the same conditions exhibits four anodic (I, II, III and III') and three cathodic (IV', IV and V) current contributions (Fig. 2). The increase in charge produced during cycling is principally related to the conjugated redox contributions III-III' and IV-IV'. The assignment of

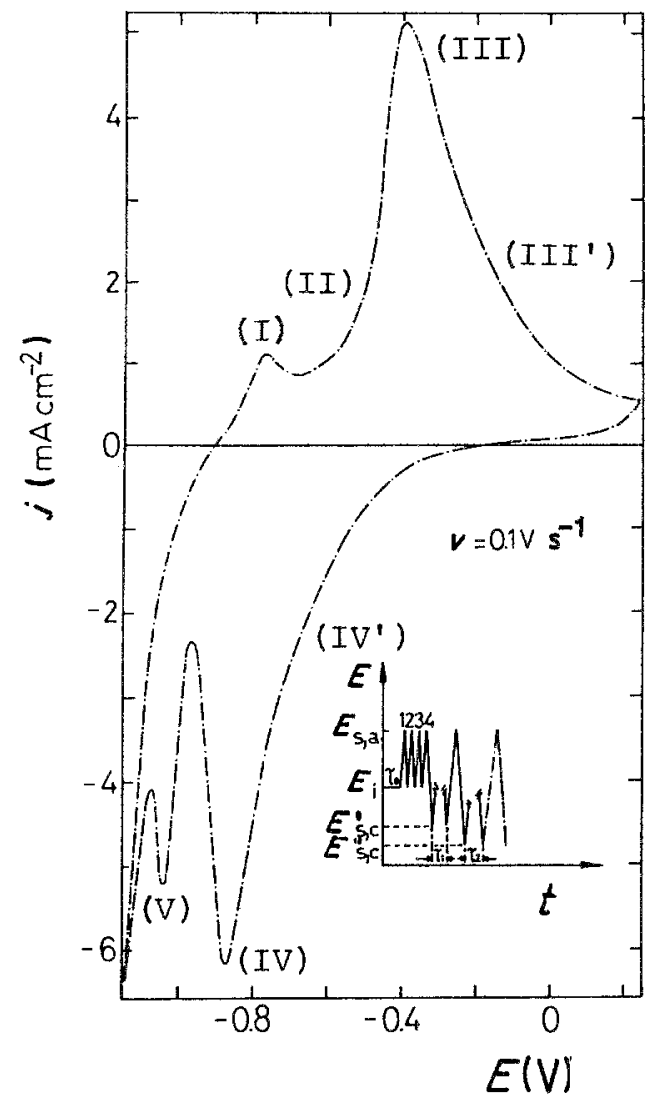

Fig. 2. Stabilized RTPS voltammogram obtained with an iron electrode in $0.1 \mathrm{M} \mathrm{KOH}$ at $v=0.1 \mathrm{~V} \mathrm{~s}^{-1}$ between $E_{\mathrm{s}, \mathrm{a}}=0.24 \mathrm{~V}$ and $E_{\mathrm{s}, \mathrm{c}}^{\prime}=-1.16 \mathrm{~V}$ after the perturbing potential programme indicated in the figure. $E_{\mathrm{j}}=-0.66 \mathrm{~V} ; E_{\mathrm{s}, \mathrm{c}}^{\prime}=-0.96 \mathrm{~V} ; E_{\mathrm{s}, \mathrm{c}}^{\prime \prime}=-1.16 \mathrm{~V}$; $\tau_{0}=1 \mathrm{~min} ; \tau_{1}=37 \mathrm{~min} ; \tau_{2}=23 \mathrm{~min}$.

the different current peaks and humps has already been made in previous publications concerning the voltammetry of iron in strongly alkaline solutions $[8,17]$. Results shown in Figs 1 and 2 indicate that the charge accumulation related to peaks III-III'/IV-IV', reported earlier for freshly electroreduced iron electrodes [17], also occurs for iron electrodes previously covered with an anodic layer formed at $E_{\mathrm{i}}=-0.66 \mathrm{~V}$. The charge accumulation depends mainly on switching potential values, on cycling time, and on potential scan rate.

The voltammetric response of the chemically precipitated iron hydroxide electrode depends on the iron hydroxide layer preparation procedure, on the number of potential cycles, and on $E_{\mathrm{i}}, E_{\mathrm{s}, \mathrm{c}}$ and $E_{\mathrm{s}, \mathrm{a}}$. Thus, when the voltammetric measurement is preceded by a potential holding at $E_{\mathrm{i}}=0.24 \mathrm{~V}$ for $\tau_{0}=1 \mathrm{~min}$, the voltammogram at $v=0.1 \mathrm{~V} \mathrm{~s}^{-1}$ in the $E_{\mathrm{s}, \mathrm{c}}=-0.96 \mathrm{~V}$ to $E_{\mathrm{s}, \mathrm{a}}=0.90$ range (Fig. 3) changes considerably during cycling and, in contrast to the bulk iron substrate electrode, the voltammetric charge decreases. Thus, the first potential cycle shows two well-defined current peaks, one cathodic at ca $-0.60 \mathrm{~V}\left(\mathrm{C} 4^{\prime}\right)$ and another anodic at ca $-0.35 \mathrm{~V}$ (A3). Peak C4' partly overlaps a small contribution (C4) which appears practically as a hump located at $-0.80 \mathrm{~V}$. The charge of peak $\mathrm{C4}^{\prime}$ diminishes during cycling, whereas that of peak $\mathrm{C} 4$ increases. It is interesting to note that the potentials of peaks $\mathrm{C}^{\prime}$ and $\mathrm{C} 4$ are directly comparable 


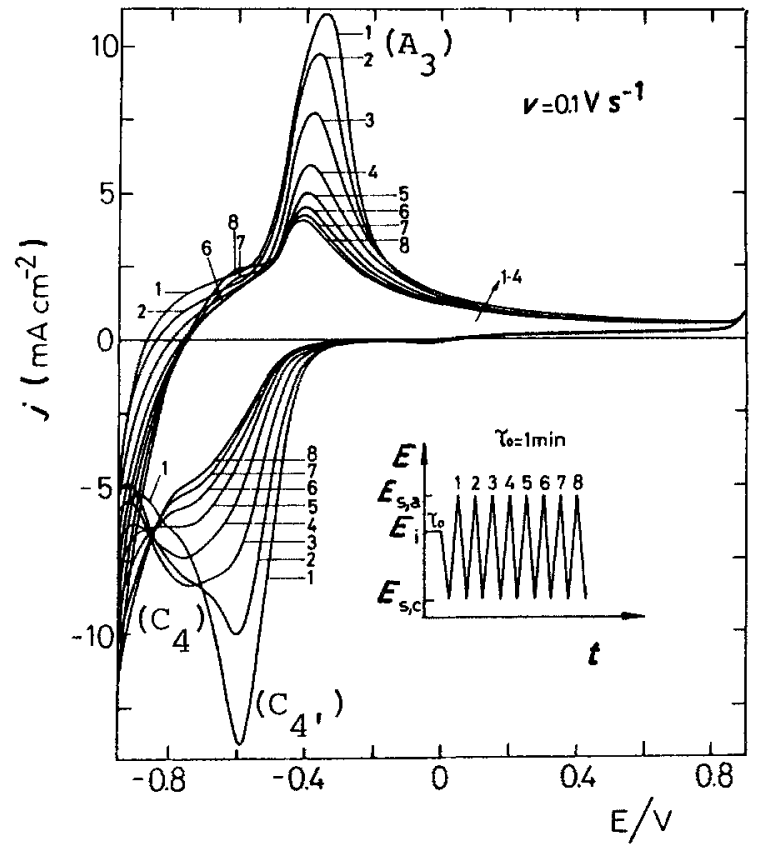

Fig. 3. RTPS voltammograms obtained at $v=0.1 \mathrm{~V} \mathrm{~s}^{-1}$ with a precipitated hydrous iron hydroxide electrode on $\mathrm{Pt}$ for $n=50,0.1 \mathrm{M}$ $\mathrm{FeSO}_{4}$ (solution I) and in $0.1 \mathrm{M} \mathrm{KOH}+0.3 \mathrm{M} \mathrm{K}_{2} \mathrm{SO}_{4}$ (solution In). $E_{\mathrm{i}}=0.24 \mathrm{~V} ; E_{\mathrm{s}, \mathrm{a}}=0.89 \mathrm{~V} ; E_{\mathrm{s}, \mathrm{c}}=-0.96 \mathrm{~V} ; \tau_{0}=1 \mathrm{~min}$.

to those of peaks IV' and IV resulting for massive iron electrodes, although their relative contributions in both cases differ remarkably (see, for instance, Figs 2 and 3). Similarly, the potential of peak A3 is nearly the same as that of peak III. Otherwise, peak A3 involves, at its ascending branch, a small current plateau, its location and magnitude depending on the potential cycling time (Fig. 3).

Voltammograms performed by varying $E_{\mathrm{s}, \mathrm{c}}$ stepwise and setting $E_{\mathrm{s}, \mathrm{a}}$ at a value within the passive region, allow following of the voltammetric changes involving the different oxidation levels of the iron-containing surface species. Thus, at a constant $v$, the electrooxidation response of cathodic reaction products in the active surface layer is mainly determined by the value of $E_{\mathrm{s}, \mathrm{c}}$. Accordingly, this effect is also reflected in the subsequent positive-going potential scan. For $E_{\mathrm{s}, \mathrm{a}}=0.24 \mathrm{~V}$ (Fig. 4) and $E_{\mathrm{i}}=E_{\mathrm{s}, \mathrm{c}}=-0.66 \mathrm{~V}$, that is, $E_{\mathrm{s}, \mathrm{c}}$ covering the potential range of the main current contributions $\mathrm{A} 3$ and $\mathrm{C}^{\prime}$, the voltammogram closely resembles that already described (see, for instance, Fig. 3), although the charge associated with the highly symmetric cathodic peak decreases slightly during cycling (dashed curves in Fig. 4). As $E_{\mathrm{s}, \mathrm{c}}$ is set more negatively, i.e. $E_{\mathrm{s}, \mathrm{c}}=E_{\mathrm{s}, \mathrm{c}}^{\prime}=-1.06 \mathrm{~V}$, the voltammogram exhibits drastic changes in location and magnitude of the different current peaks. In this case, the first positive-going potential excursion from $E_{\mathrm{s}, \mathrm{c}}^{\prime}=$ $-1.06 \mathrm{~V}$ (Fig. 4, curve 4) shows a complex anodic current profile with at least four distinguishable contributions ( $\mathrm{A} 1, \mathrm{~A} 2, \mathrm{~A} 3$ and $\mathrm{A} 3^{\prime}$ ) located at potential values close to those of peaks I, II, III and III' in Fig. 2. The charge resulting from peaks $\mathrm{A} 3-\mathrm{A3}^{\prime}$ (Fig. 4, curve 4) is about the same as that resulting from the initial potential scan (Fig. 4 curve 1). However, during the subsequent reverse scan, the contribu-

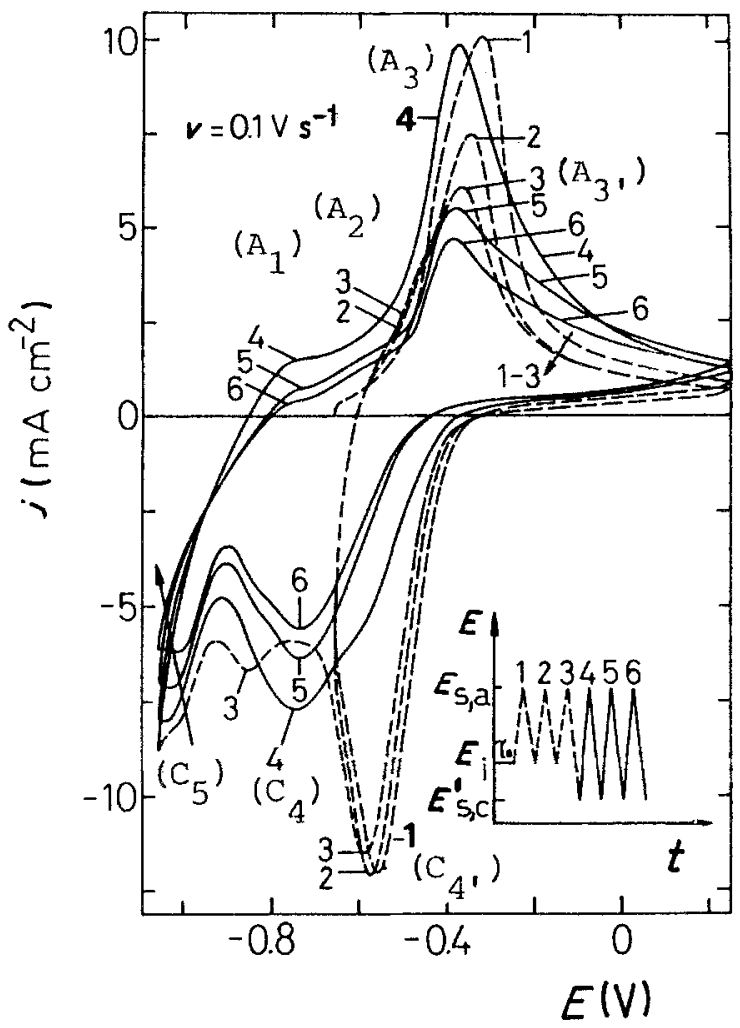

Fig. 4. Influence of $E_{s, c}$ on the voltammograms obtained with the perturbing potential programme depicted in the figure for a precipitated hydrous iron hydroxide electrode on Pt formed as indicated in Fig. 3. $E_{\mathrm{i}}=-0.66 \mathrm{~V} ; E_{\mathrm{s}, \mathrm{a}}=0.24 \mathrm{~V} ; E_{\mathrm{s}, \mathrm{c}}^{\prime}=-1.06 \mathrm{~V} ; \tau_{\mathrm{p}}=1 \mathrm{~min}$.

tion $\mathrm{C}^{\prime}$ decreases strongly in favour of two new emerging peaks, $\mathrm{C} 4$ and $\mathrm{C} 5$, which are, in principle, comparable to peaks $\mathrm{IV}$ and $\mathrm{V}$ in the voltammogram of massive iron electrodes. Otherwise, peak $\mathrm{C}^{\prime}$ practically disappears as $E_{\mathrm{i}}$ is set more negative than peak C4 (Fig. 5). From these results one can conclude that the contributions $\mathrm{A} 1$ and $\mathrm{A} 2$ become clearly detectable as $E_{\mathrm{s}, \mathrm{c}}$ is set in the potential range of peak $\mathrm{C} 5$, but on the other hand peak $\mathrm{C}^{\prime}$ can then no longer be observed. Likewise, the characteristics of peak A3 depend both on $E_{\mathrm{s}, \mathrm{c}}$ and on the potential cycling. Moreover, at constant $E_{\mathrm{s}, \mathrm{c}}$ and $E_{\mathrm{s}, \mathrm{a}}$, the voltammetric charge decreases during cycling, but as $E_{\mathrm{s}, \mathrm{c}}$ is shifted more negatively, the overall charge begins to increase.

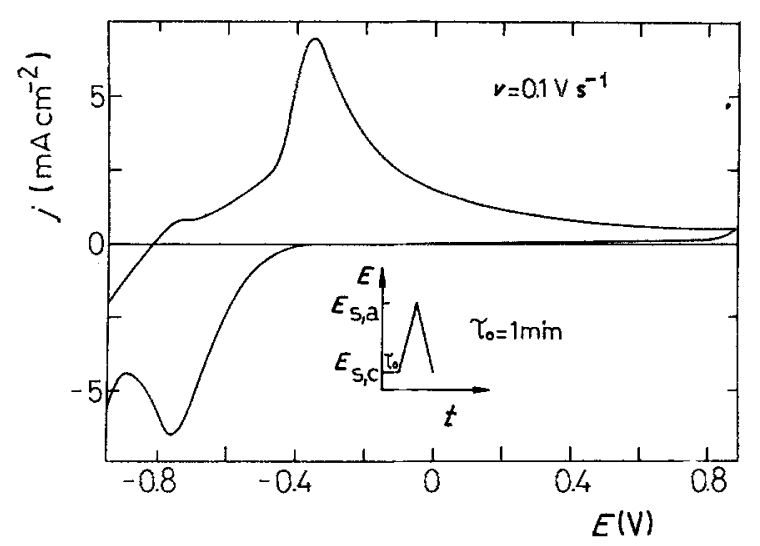

Fig. 5. STPS voltammogram run at $v=0.1 \mathrm{~V} \mathrm{~s}^{-1}$ between $E_{\mathrm{s}, \mathrm{c}}=-0.96 \mathrm{~V}$ and $E_{\mathrm{s}, \mathrm{a}}=0.89 \mathrm{~V}$ with a precipitated hydrous iron hydroxide electrode on $\mathrm{Pt}$ for $n=50,0.1 \mathrm{M} \mathrm{FeSO}_{4}$ (solution I) and $0.1 \mathrm{M} \mathrm{KOH}$ (solution II). 


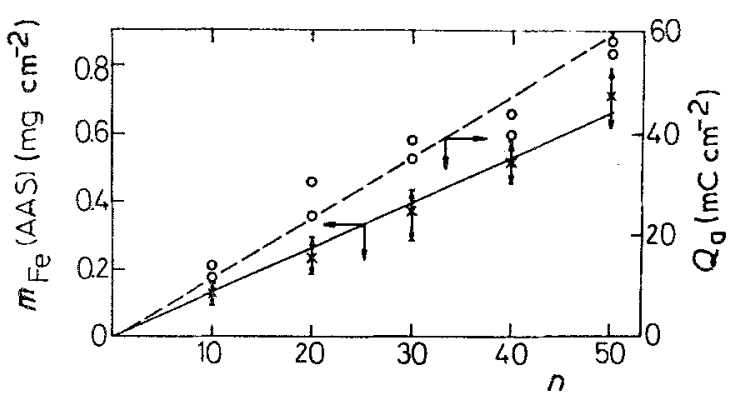

Fig. 6. Dependence of $n$ in the precipitated iron hydroxide electrode preparation procedure on $m_{\mathrm{Fe}}$, as evaluated by atomic absorption spectroscopy $(\mathrm{x})$, and on $Q_{\mathrm{a}}$ as determined from voltammetric runs (O) performed under conditions indicated in Fig. 5 .

These observations apply to all iron hydroxide electrodes, independently of the amount of precipitated active material. It should be noted, that for freshly prepared electrodes the amount of chemically precipitated iron hydroxide evaluated through atomic absorption spectroscopy, $m_{\mathrm{Fe}}$ (AAS), increases linearly with $n$ (Fig. 6). Likewise, the anodic voltammetric charge, $Q_{\mathrm{a}}$, also increases linearly with $n$, but for constant $n$ and concentration of the precipitating solutions, the values of $Q_{\mathrm{a}}$ turn out to be considerably smaller than those expected from $m_{\mathrm{Fe}}$ (AAS).

The conjugated electrooxidation/electroreduction process associated with peaks $\mathrm{A} 3$ and $\mathrm{C} 4$ ' depends to some extent on the perturbing potential conditions, particularly on $v$ (Figs 7 and 8). For $E_{\mathrm{i}}=E_{\mathrm{s}, \mathrm{c}}=$ $-0.66 \mathrm{~V}$, one can observe a peak multiplicity in the contributions $\mathrm{A} 3$ and $\mathrm{C}^{\prime}$ either by including a poten-

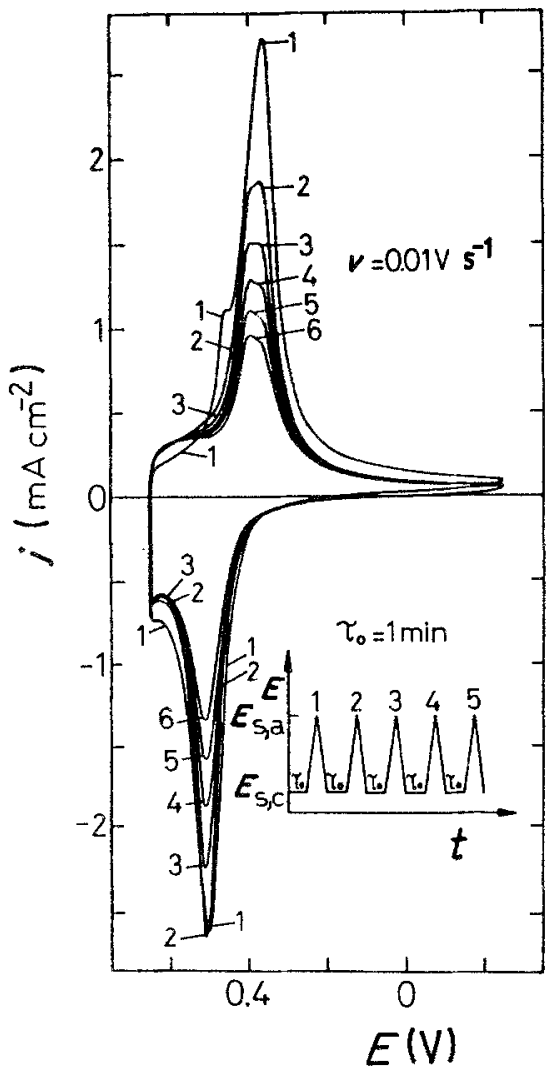

Fig. 7. Voltammograms obtained at $v=0.01 \mathrm{Vs}^{-1}$ from $E_{\mathrm{s}, \mathrm{c}}=$ $-0.66 \mathrm{~V}$ to $E_{\mathrm{s}, \mathrm{a}}=0.24 \mathrm{~V}$ after holding at $E_{\mathrm{s}, \mathrm{c}}$ during $\tau_{0}=1 \mathrm{~min}$ before each potential cycle. Precipitated hydrous iron hydroxide electrode on Pt formed is indicated in Fig. 3.

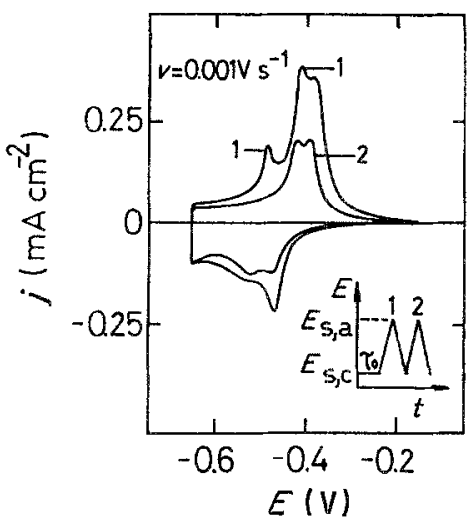

Fig. 8. Voltammograms run at $v=0.001 \mathrm{~V} \mathrm{~s}^{-1}$ with a precipitated hydrous iron hydroxide electrode on Pt formed as indicated in Fig. 5. $E_{\mathrm{s}, \mathrm{c}}=-0.66 \mathrm{~V} ; E_{\mathrm{s}, \mathrm{a}}=-0.16 \mathrm{~V} ; \tau_{0}=2 \mathrm{~min}$

tial hold at $E_{\text {s.c }}$ for a time $\tau_{0}=1 \mathrm{~min}$ in the voltammetry at $v=0.01 \mathrm{Vs}^{-1}$ (Fig. 7), or by using a lower $v$, i.e. $v=0.001 \mathrm{~V} \mathrm{~s}^{-1}$ (Fig. 8). As $v$ decreases the peak multiplicity can be better resolved and the reversibility of the conjugated redox system, defined through the potential difference between the main anodic and cathodic current peaks, increases remarkably.

Comparable voltammograms were also obtained by using active iron hydroxide layers prepared on a massive iron electrode (Fig. 9). In this case, the voltammograms are qualitatively similar (see Figs 4 and 9), but the relative contributions of the different reactions are appreciably modified.

The cathodic current transients were run under constant potential steps, $E_{\mathrm{f}}$, set in the -0.55 to $-0.85 \mathrm{~V}$ range by using freshly prepared iron hydroxide electrodes which were previously anodized at $E_{\mathrm{i}}=0.25 \mathrm{~V}$ for Is (Fig. 10). These current transients exhibit a small current arrest which becomes better defined when $E_{\mathrm{f}} \geqslant-0.70 \mathrm{~V}$, that is, when $E_{\mathrm{f}}$ lies in the poten-

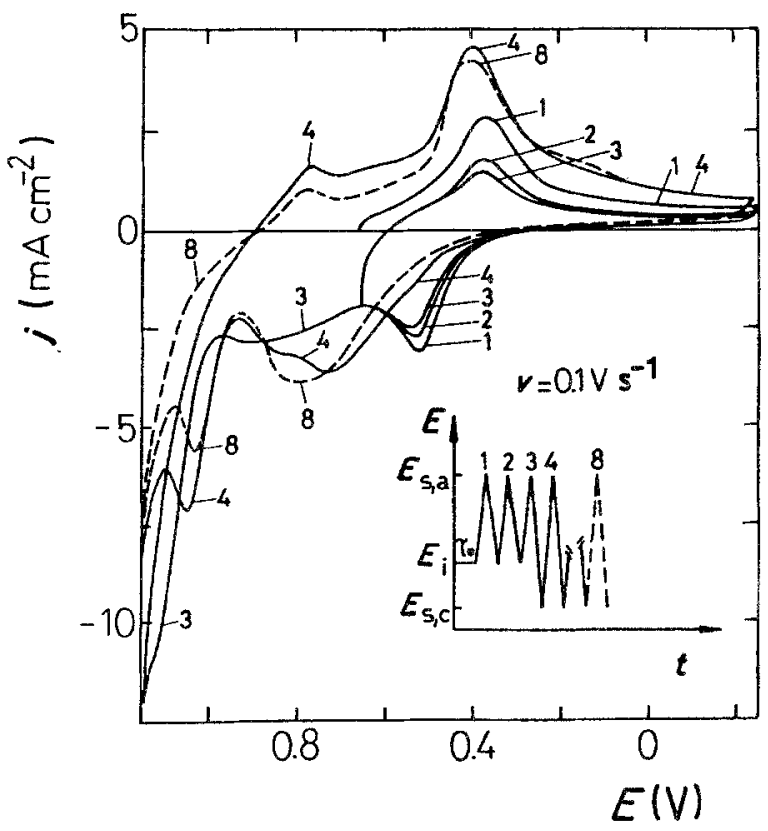

Fig. 9. Influence of the cathodic switching potential on the voltammograms obtained at $v=0.1 \mathrm{Vs}^{-1}$ with a precipitated hydrous iron hydroxide electrode on freshly polished $\mathrm{Fe}, n=50,0.1 \mathrm{M}$ $\mathrm{FeSO}_{4}$ (solution I) and in $0.1 \mathrm{M} \mathrm{KOH}$ (solution II). $E_{\mathrm{i}}=-0.66 \mathrm{~V}$; $E_{\mathrm{s}, \mathrm{a}}=0.24 \mathrm{~V} ; E_{\mathrm{s}, \mathrm{c}}=-1.16 \mathrm{~V} ; \tau_{0}=1 \mathrm{~min}$. 


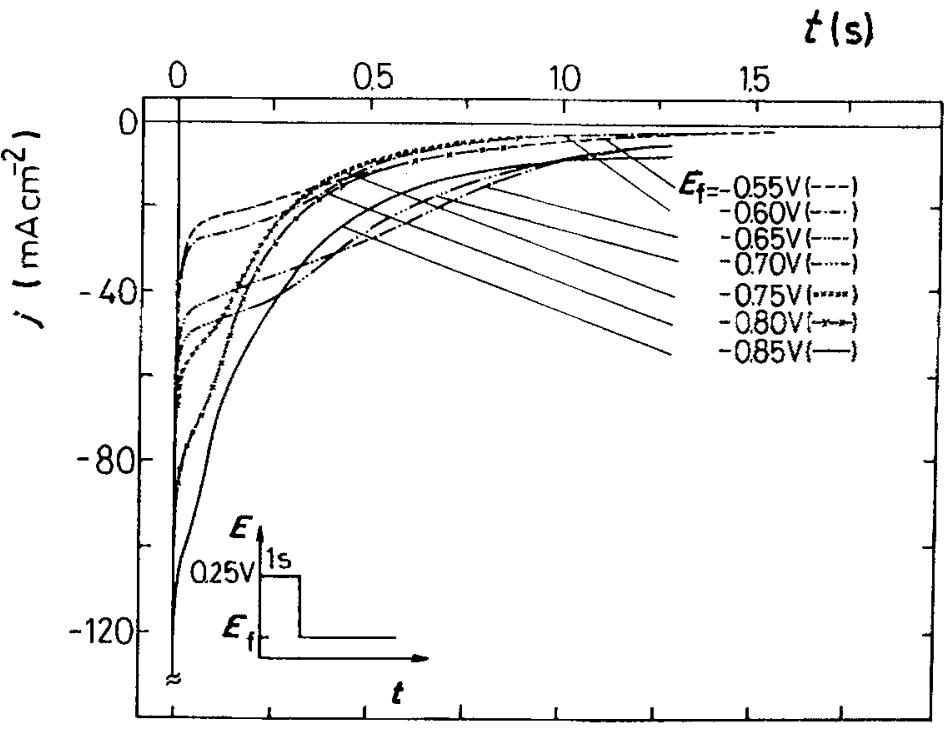

Fig. 10. Cathodic current transients for $E_{\mathrm{i}}=0.25 \mathrm{~V}$ during Is up to different $E_{\mathrm{f}}$ values with precipitated hydrous iron hydroxide electrodes on Pt prepared as described in Fig. 5, before potentiostatic pulse was applied.

tial range of peak $\mathrm{C}^{\prime}$. This current arrest practically disappears when $E_{\mathrm{f}}$ is set extremely negative, i.e. $-0.85 \mathrm{~V}$. Likewise, it should be noticed that the cathodic current transients become very sensitive to the history of the active electrode material (Fig. 11). For instance, a net difference in the cathodic transients can be noticed for an oxide layer which has been potentiostatically oxidized (Fig. 11, curve A) as compared to that which has been subjected to a combined potential sweep and potential step programme preceding the potentiostatic electroreduction (Fig. 11, curve B). For case $A$ a clear current arrest can be observed and the corresponding electroreduction charge becomes considerably greater than for case $\mathbf{B}$. These results can be also related to the presence or absence, respectively, of current peak $\mathrm{C}^{\prime}$ in the corresponding voltammograms.

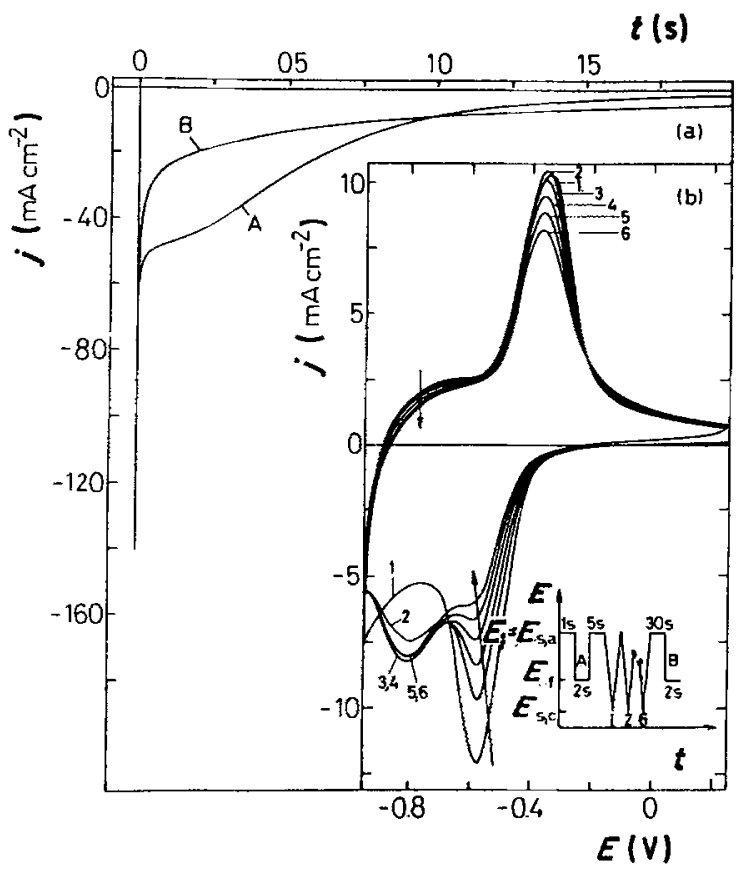

Fig. 11. Cathodic current transients (a) and voltammograms (b) obtained with a precipitated hydrous iron hydroxide electrode on $\mathrm{Pt}$ formed as indicated in Fig. 5. The perturbing potential programme is shown in the figure. $E_{\mathrm{i}}=E_{\mathrm{s}, \mathrm{a}}=0.25 \mathrm{~V} ; E_{\mathrm{s}, \mathrm{c}}=-0.96 \mathrm{~V}$; $E_{\mathrm{f}}=-0.70 \mathrm{~V}$.
To gain further information about the changes produced in the characteristics of the precipitated hydrous iron hydroxide layer according to the influence of the electroreduction level reached at $E_{\mathrm{s}, \mathrm{c}}$, steadystate polarization curves with a ferro/ferricyanide electron-transfer reaction were performed. The test reaction was studied within the potential window where the oxide layer is passive. The corresponding potentiostatic Tafel plots (Fig. 12) obtained with a freshly prepared iron hydroxide layer (A) and with a similarly formed electrode, but previously cycled at $v=0.1 \mathrm{Vs}^{-1}$ between $E_{\mathrm{s}, \mathrm{a}}=0.24 \mathrm{~V}$ and $E_{\mathrm{s}, \mathrm{c}}=-0.96 \mathrm{~V}$ in plain $0.1 \mathrm{M} \mathrm{KOH}(\mathrm{B})$, show a

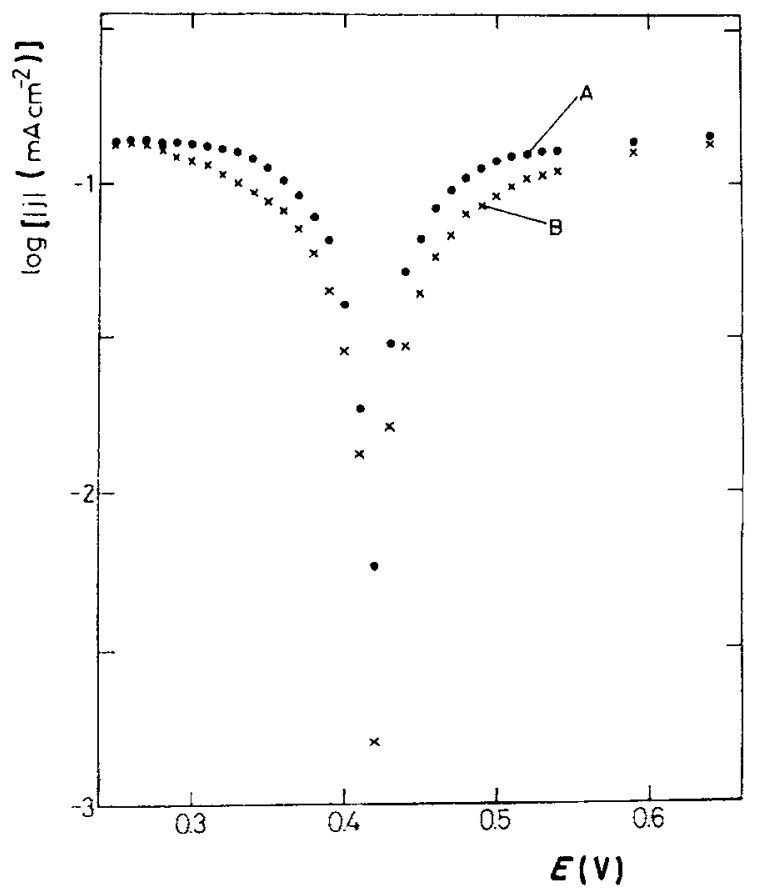

Fig. 12. Stationary polarization curves run on the $\mathrm{Pt} /$ precipitated hydrous iron hydroxide electrode immersed in $0.1 \mathrm{M} \mathrm{KOH}+$ $0.005 \mathrm{M} \mathrm{K} \mathrm{K}_{3}\left[\mathrm{Fe}(\mathrm{CN})_{6}\right]+0.005 \mathrm{M} \mathrm{K} \mathrm{K}_{4}\left[\mathrm{Fe}(\mathrm{CN})_{6}\right]$ with electrodes formed as indicated in Fig. 5. Freshly prepared electrode (curve A). Electrode previously subjected to 10 potential cycles at $v=$ $0.1 \mathrm{~V} \mathrm{~s}^{-1}$ between $E_{\mathrm{s}, \mathrm{a}}=0.24 \mathrm{~V}$ and $E_{\mathrm{s}, \mathrm{c}}=-0.96 \mathrm{~V}$ in $0.1 \mathrm{M} \mathrm{KOH}$ solution (curve B). 
decrease in the potential difference between the anodic and cathodic partial reactions for case $\mathrm{A}$. This difference suggests that the electronic conduction at the chemically deposited iron hydroxide layer is slowed down, presumably due to structural changes promoted through the perturbing potential.

\section{Discussion}

Let us first consider the equilibrium potential values of the different possible reactions of iron, water and corresponding ions at $\mathrm{pH} 13$ (Table 1) [44]. It is clear that, thermodynamically, the potential range covered by the experiments involves all the oxidation levels of iron. In this respect the values of $E_{\mathrm{s}, \mathrm{c}}$ and $E_{\mathrm{s}, \mathrm{a}}$ in voltammetric runs play a very important role in determining electrochemical reactions where the reactant and products imply intermediate oxidation levels of the iron surface species.

By comparing Figs 1, 2 and 3, one can observe that the potential cycling of the iron hydroxide electrode on the iron substrate produces a gradual increase in voltammetric charge in contrast to the response of the iron hydroxide electrodes on platinum substrates. Furthermore, from data shown in Figs 2 and 3, it is seen that, during the oxidation-reduction cycles, the voltammogram of the iron hydroxide electrode prepared on platinum, which initially resembles to some extent that resulting from the anodized iron electrode, progressively acquires a different shape. This change is consistent with the fact that the composition and structure of the oxide layer, in the absence of bulk iron metal electrodissolution, becomes different from that resulting from the direct anodization of an iron electrode. Likewise, that voltammetric difference precludes the formation of $\mathrm{Fe}(\mathrm{O})$ in the electroreduction reaction of the iron hydroxide layer on platinum, since if this were the case, one would expect a closer voltammetric behavior of both types of electrode.

The voltammograms resulting during the oxidationreduction cycles for precipitated iron hydroxide layers exhibit a clear isopotential close to $-0.8 \mathrm{~V}$ which can be taken as further indication of changes in the structure of the iron hydroxide layer during the oxidationreduction cycles. The layer resulting after prolonged cycling offers a voltammetric response considerably more irreversible than that observed initially. This fact, which correlates to the electrochemical behaviour of the ferro/ferricyanide redox couple as seen in Fig. 11, indicates that a passive layer is gradually built up during the oxidation-reduction cycles at the expense of the initially precipitated layer.

The voltammetric behaviour of the iron hydroxide electrode on platinum can be explained by considering the properties of the precipitated layer. The iron hydroxide layer on platinum obtained through chemical precipitation involves a hydrous mixture of

Table 1. Equilibrium potentials at pHI3 calculated for $\mathrm{Fe}(\mathrm{OH})_{2}$ and $\mathrm{Fe}(\mathrm{OH})_{3}$ saturation conditions from $\mathrm{Ref}$. [44]

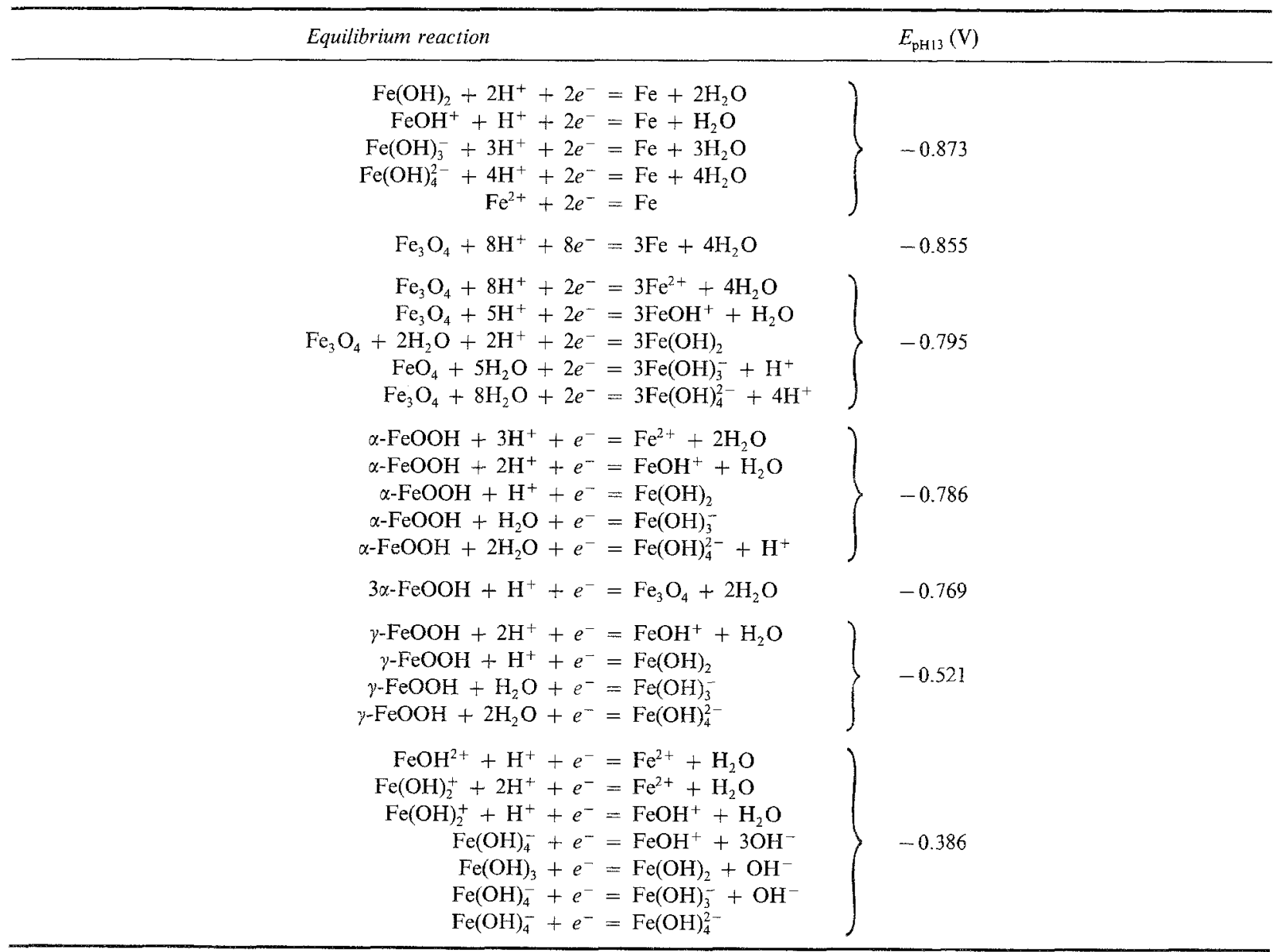


$\mathrm{Fe}(\mathrm{OH})_{2}$ and $\mathrm{FeOOH}$ species [41] which participate, initially, in a global reaction which can be written as follows:

$$
\begin{gathered}
{\left[\mathrm{Fe}(\mathrm{OH})_{2}\right]_{x_{1}}[\mathrm{FeOOH}]_{y_{1}} z_{1} \mathrm{H}_{2} \mathrm{O}} \\
\rightleftarrows\left[\mathrm{Fe}(\mathrm{OH})_{3}\right]_{x_{2}}[\mathrm{FeOOH}]_{y_{2}} z_{2} \mathrm{H}_{2} \mathrm{O}+\mathrm{H}^{+}+e^{-}
\end{gathered}
$$

According to data compiled in Table 1, reaction 1 can be justified for $E_{s, \mathrm{c}}$ values more positive than about $-0.7 \mathrm{~V}$. Otherwise, the course of this reaction depends on the layer thickness, i.e. on $n$, and on the cycling time. Thus, for the initial potential scan $y_{1} \approx y_{2}$, $x_{1} \approx x_{2}$ and $z_{2}=z_{1}-1$ whereas as the cycling time increases $y_{2} \rightarrow y_{1}+x_{1}$ and $x_{2} \rightarrow 0$. Furthermore, reaction 1 , which can be related to the pair of peaks $\mathrm{A} 3 / \mathrm{C}^{\prime}$, also implies that the water content in the oxide layer decreases during the electrooxidation half cycle. It should be mentioned that Nagayama and Kawamura [45] postulated a two-layer model of the film, consisting of an insulating outer layer of hydrated $\mathrm{Fe}(\mathrm{OH})_{3}$ and an inner layer of conducting $\gamma$-FeOOH.

The situation just described changes drastically when $E_{\mathrm{s}, \mathrm{c}}$ is set at potentials lower than $-0.7 \mathrm{~V}$. Under these circumstances the electroreduction of the Fe(III) species to $\mathrm{Fe}_{3} \mathrm{O}_{4}$ becomes feasible according to the overall process [46]

$$
\begin{gathered}
3[\mathrm{FeOOH}] y_{2} \mathrm{H}_{2} \mathrm{O}+e^{-} \\
\rightleftarrows \mathrm{Fe}_{3} \mathrm{O}_{4}+\mathrm{OH}^{-}+\left(y_{2}+1\right) \mathrm{H}_{2} \mathrm{O}
\end{gathered}
$$

as the corresponding equilibrium potential is nearly $-0.8 \mathrm{~V}$ at $\mathrm{pH} 13$. Figure 4 shows that reaction 2 is actually completed after at least a few potential cycles. Likewise, Fig. 3 also indicates that the gradual disappearance of peak $\mathrm{C}^{\prime}$ in favour of peak $\mathrm{C} 4$ is a consequence of the progressive replacement of the $\mathrm{Fe}(\mathrm{OH})_{2}$ component in the primitive hydrous oxide layer by $\mathrm{Fe}_{3} \mathrm{O}_{4}$ during potential cycling [40]. The structure of the resulting layer exhibits the largest depolarization for the HER at $-0.9 \mathrm{~V}$ and the smallest voltammetric charge associated with the iron hydroxide electrochemical reactions. The formation of a relatively large amount of $\mathrm{Fe}_{3} \mathrm{O}_{4}$ at this stage means that the hydrous state of the oxide layer has now been changed into that of a layer exhibiting electronic conducting resistance through $\mathrm{Fe}_{3} \mathrm{O}_{4}$ and poorer proton transfer properties [29, 47]. Therefore, the electroreduction of the hydrous $\mathrm{FeOOH}$ constituent in the iron hydroxide layer can follow two simultaneous pathways:

$$
\begin{gathered}
\mathrm{Fe}^{2+}+3 \mathrm{OH}^{-} \rightleftarrows \mathrm{Fe}(\mathrm{OH})_{2}+\mathrm{OH}^{-} \\
\mathrm{FeOOH}+\mathrm{H}_{2} \mathrm{O} \stackrel{\left(+\mathrm{Fe}^{2+}+2 \mathrm{OH}^{-}+\mathrm{FeOOH}\right)}{\longrightarrow} \mathrm{Fe}_{3} \mathrm{O}_{4}+3 \mathrm{H}_{2} \mathrm{O}
\end{gathered}
$$

$$
3 \mathrm{Fe}(\mathrm{OH})_{2}+2 \mathrm{OH}^{-} \rightleftarrows \mathrm{Fe}_{3} \mathrm{O}_{4}+4 \mathrm{H}_{2} \mathrm{O}+2 e^{-}
$$

Accordingly, $\mathrm{Fe}_{3} \mathrm{O}_{4}$ phase formation can occur either electrochemically, through reactions 3 and 5 , or chemically, through reaction 4 .

It is possible that under prolonged cathodization at $-0.89 \mathrm{~V}, \mathrm{FeOH}^{+}$species can be formed and further electrooxidized at ca. $-0.8 \mathrm{~V}$, according to the following reactions:

$$
\begin{aligned}
& 3 \mathrm{FeOH}^{+}+5 \mathrm{OH}^{-}=4 \mathrm{H}_{2} \mathrm{O}+\mathrm{Fe}_{3} \mathrm{O}_{4}+2 e^{-} \\
& \mathrm{FeOOH}+\mathrm{H}_{2} \mathrm{O}+e^{-}=\mathrm{FeOH}^{+}+2 \mathrm{OH}^{-}
\end{aligned}
$$

These conclusions agree with previous explanations advanced by Tamura et al. [40]. The appearance of peak $\mathrm{Al}$ in the voltammogram depicted in Fig. 5 can be understood in terms of reactions 6 and 7 . But the fact that the amount of active material tends to be lower than that predicted by chemical analysis also indicates that $\mathrm{Fe}_{3} \mathrm{O}_{4}$ is already present in the oxide layer from the beginning of the experiments (see Fig. 6).

\section{Conclusions}

(i) The voltammetric behaviour of iron hydroxide layers precipitated on platinum can be compared to that obtained after prolonged potential cycling of iron electrodes in alkaline media.

(ii) Redox processes at iron hydroxide layers are strongly influenced by the electroreduction level of the hydroxide layer achieved in the charge-discharge cycles.

(iii) The change in the electronic conductivity of the composite iron hydroxide-oxide layer appears to be determined by the irreversible formation of $\mathrm{Fe}_{3} \mathrm{O}_{4}$-like species.

(iv) The passive layer is gradually built up during the oxidation-reduction cycles at the expense of the initially precipitated layer. This conclusion is also drawn from the kinetic behaviour of the ferro/ ferricyanide redox couple reaction.

\section{Acknowledgements}

This work was financially supported by the Consejo Nacional de Investigaciones Científicas y Técnicas and the Comisión de Investigaciones Científicas de la Provincia de Buenos Aires.

\section{References}

[1] U. Stimming, J. Electroanal. Chem. 136 (1982) 345.

[2] M. E. Vela, J. R. Vilche and A. J. Ariva, in 'Passivity of Metals and Semiconductors, (edited by M. Froment), Elsevier, Amsterdam (1983) pp. 5965.

[3] M. Stratmann, K. Bohnenkamp and H. J. Engel, Corros. Sci. 23 (1983) 969.

[4] H. Worch, W. Forker and D. Rahner, Werkst. Korros. 34 (1983) 402

[5] C. Fierro, R. E. Carbonio, D. Scherson and E. B. Yeager, J. Phys. Chem. 91 (1987) 6579.

[6] G. Nazri, E. Yeager and B. D. Cahan, Tech. Rep. No. 1, Proj. NR SRO-009/7-30-79, Case Western Reserve University, Cleveland (1981).

[7] K. E. Heusler, in 'Encyclopedia of Electrochemistry of the Elements' (edited by A. J. Bard), Marcel Dekker, New York (1982) Vol. 9A, pp. 229-381.

[8] R. S. Schrebler Guzmán, J. R. Vilche and A. J. Arvia, Electrochim. Acta 24 (1979) 395. 
[9] G. Paruthinal Kalaignan, V. S. Muralidharan and K. I. Vasu, J. Appl. Electrochem. 17 (1987) 1083.

[10] K. Micka and I. Rousar, Electrochim. Acta 29 (1984) 1411.

[11] E. J. Cairns and E. H. Hietbrink, in 'Comprehensive Treatise of Electrochemistry' (edited by J. O'M. Bockris, B. E. Conway, E. Yeager and R. White), Plenum Press, New York (1981) pp. 341-370.

[12] H. G. Silver and E. Yekas, J. Electroanal. Chem. 117 (1970) 5.

[13] J. M. Lecuire and Y. Pillet, J. Electrochem. Soc. 91 (1978) 99.

[14] W. W. Frenier and F. B. Growcock, Corrosion 40 (1984) 663.

[15] R. Freour, Electrochim. Acta 30 (1985) 795.

[16] M. Ya. Plotnikov, K. M. Lazorenko-Manevich, L. A. Sokolova and V. G. Plotnikov, Elektrokhimiya 14 (1978) 344.

[17] R. S. Schrebler Guzmán, J. R. Vilche and A. J. Arvia, $J$. Appl. Electrochem. 11 (1981) 551.

[18] D. M. Drazic and Chen Shen Hao, Electrochim. Acta 27 (1982) 1409

[19] R. S. Schrebler Guzmán, J. R. Vilche and A. J. Arvia, Anal. Asoc. Quim. Arg. 70 (1982) 999.

[20] R. Peat and L. M. Peter, J. Electroanal. Chem. 228 (1987) 351.

[21] J. Dunnwald and A. Otto, Z. Anal. Chem. 319 (1984) 738

[22] Z. Q. Huang and J. L. Ord, J. Electrochem. Soc. 132 (1985) 24.

[23] T. Zakroczymski, C. J. Fen and Z. Szklarska-Smialowska, J. Electrochem. Soc. 132 (1985) 2862.

[24] C. Gutiérrez and M. A. Martinez, J. Electrochem. Soc. 133 (1986) 1873

[25] Y. Geronov, T. Tomov and S. Georgiev, J. Appl. Electrochem. 5 (1975) 351.

[26] W. E. O'Grady, J. Electrochem. Soc. 127 (1980) 557.

[27] N. Brinda-Konopik, H. Neugebauer, G. Gidaly and G. Nauer, Mikrochim Acta 9 (1981) 329.
[28] O. A. Albani, J. O. Zerbino, J. R. Vilche and A. J. Ariva, Electrochim. Acta 31 (1986) 1403.

[29] S. Juanto, J. O. Zerbino, M. I. Miguez, J. R. Vilche and A. J. Ariva, Electrochim. Acta 32 (1987) 1743.

[30] K. Ogura, A. Fujishima and K. Honda, J. Electrochem. Soc. 131 (1984) 344.

[31] K. Ogura, A. Fujishima, Y. Nagae and K. Honda, J. Electroanal. Chem. 162 (1984) 241.

[32] S. Haupt and H. H. Strehblow, Langmuir 3 (1987) 873.

[33] S. Haupt, C. Calinski, U. Collisi, H. W. Hoppe, H. D. Speckmann and H. H. Strehblow, Surf. Interf. Anal. 9 (1986) 357.

[34] C. L. Foley, J. Kruger and C. J. Bechtoldt, J. Electrochem. Soc. 114 (1967) 994

[35] I. Olefjord, J. Appl. Electrochem. 5 (1975) 145.

[36] C. T. Chen and B. D. Cahan, J. Electrochem. Soc. 129 (1982) 17

[37] B. D. Cahan and C. T. Chen, J. Electrochem. Soc. 129 (1982) 474,921

[38] V. A. Macagno, J. R. Vilche and A. J. Ariva, J. Appl. Electrochem. 11 (1981) 417.

[39] M. E. Vela, J. R. Vilche and A. J. Arvia, Electrochim. Acta 31 (1986) 1633.

[40] Y. Tamaura, Ch. Kameshima and T. Katsura, J. Electrochem. Soc. 128 (1981) 1447.

[41] J. W. Schultze, S. Mohr and M. M. Lohrengel, J. Electroanal. Chem. 154 (1983) 57.

[42] V. A. Macagno and J. R. Vilche, Monogr. Acad. Nac. Cs. Ex. Fis. Nat. Buenos Aires (1982) Vol. 2, pp. 185-227.

[43] S. Ardizzone and L. Formaro, Surf. Technol. 19 (1983) 119.

[44] T. Misawa, Corros. Sci. 13 (1973) 659.

[45] M. Nagayama and S. Kawamura, Electrochim. Acta 12, (1967) 1109

[46] B. McEnaney and D. C. Smith, Corros. Sci. 20 (1980) 873

[47] S. Juanto, J. O. Zerbino, J. R. Vilche and A. J. Arvia, in 'Surface Inhibition and Passivation (edited by E. McCafferty and R. J. Brodd), The Electrochemical Society, Pennington (1986) pp. 226-238. 